University of North Florida

UNIVERSITY of

NORTH FLORIDA.

UNF Digital Commons

English Faculty Publications

Department of English

Spring 2002

\title{
Quiet Catastrophe: Robert Smithson's Spiral Jetty, Vanished
}

Clark Lunberry

University of North Florida, clark.lunberry@unf.edu

Follow this and additional works at: https://digitalcommons.unf.edu/aeng_facpub

Part of the Art and Design Commons, and the English Language and Literature Commons

\section{Recommended Citation}

Lunberry, Clark, "Quiet Catastrophe: Robert Smithson's Spiral Jetty, Vanished" (2002). English Faculty Publications. 6.

https://digitalcommons.unf.edu/aeng_facpub/6

This Article is brought to you for free and open access by the Department of English at UNF Digital Commons. It has been accepted for inclusion in English Faculty Publications by an authorized administrator of UNF Digital Commons. For more information, please contact Digital Projects.

(C) Spring 2002 All Rights Reserved

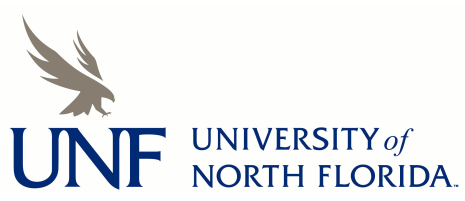




\title{
Quiet Catastrophe: Robert Smithson's Spiral Jetty, Vanished
}

\author{
—Clark Lunberry
}

\begin{abstract}
"For although we know that the years pass, that youth gives way to old age, that fortunes and thrones crumble (even the most solid among them) and that fame is transitory, the manner in which-by means of a sort of snapshot-we take cognisance of this moving universe whirled along by Time, has the contrary effect of immobilising it."
\end{abstract}

-Marcel Proust, Time Regained

"The memory of what is not may be better than the amnesia of what is."

—Robert Smithson, "Incidents of MirrorTravel in the Yucatan"

Maps to Nowhere: Seen from above, Robert Smithson's Spiral Jetty emerges dramatically from the rocky shores of Utah's Great Salt Lake. Like a swirling vortex steadied and then stilled, the earthwork begins as a straight line of stone extending far into the water, the form then curving, arching and coiling in upon itself until abruptly coming to an end. Rocks and boulders are seen in various shapes and sizes, with brown soil packed and flattened within the spiral, 
making a broad path that one might walk upon. The water washes upon the earthwork's shaped shores, surrounding and filling it, a cloudy bluish to brown on the outside, and then increasingly, a murky, milky red toward its ever tightening center, moving from still to stagnant. To the side of the Jetty, small waves break the lake's otherwise smooth surface, casting patches of light caught in their crescence; blue sky and clouds are faintly reflected on the water, the bottom of the lake occasionally glimpsed through its shallow depths. And there as well, in 1970, seen alone on the shore of the lake is the late Robert Smithson, standing in silhouette and fixed in motion, a small figure alongside the sprawling dimensions of his Spiral Jetty. For his earthwork is enormous, indeed monumental, filling the page upon which it is printed, the photograph within which both he and his Jetty are arrested and recorded. Focusing further, we can see there on the paper (the past) in the present tense and then speak it; 1970 now. The image of the object convincing - as if one were there, as if it were visible-effectively persuading of presence. The photographed stones still-rising out of the lake, off the page-an inscrutable hieroglyph, a free-floating question mark written on water.

Like Proust's immobilizing "snapshots," the many photographs of the Spiral Jetty can be observed from above as though one were flying over them, the massive earthwork chemically contracted into viewable proportion. These contained images of the object appear as flattened landscapes transported and frozen in time, framed vistas that allow the directed eyes of the viewer to visually visit the remote site in Utah. Further, the photographs enable the observer to examine in careful detail not only that which has been, but also that which has in fact vanished. For Smithson's celebrated earthwork, covered over by the risen lake, is now no longer visible, nor has it been for some time. Aside from a brief reemergence several years back, ${ }^{1}$ the inundating waters of the Great Salt Lake long ago essentially erased the stones from the scene, leaving barely a trace of the object, only the image remaining. And with its form underwater, what remains of the Spiral Jetty (along with Smithson's important parallel projects, his film and essay of the same title) are printed pictures and written documents of a material form that has otherwise disappeared.

More than any other medium, it has been photography that has most powerfully, pragmatically prolonged the life and sustained the legend of Smithson and his Spiral Jetty. ${ }^{2}$ For those widely reproduced images taken at the time of the Jetty's completion have continued to convincingly render the vanished past into a visible, accessible present, permitting a detached examination of the earthwork's phantom 


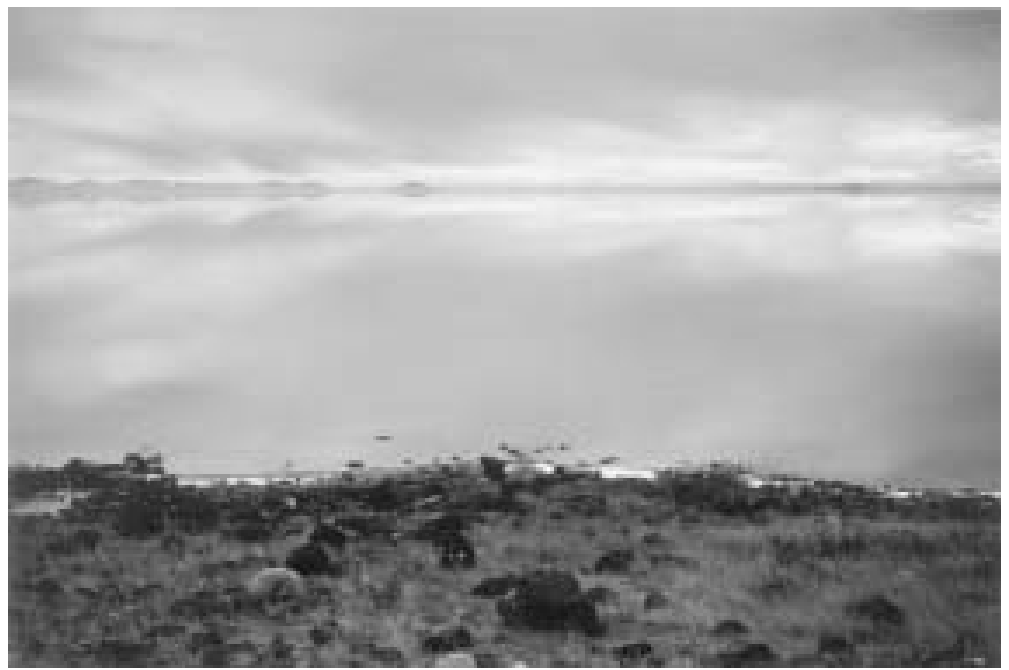

Spiral Jetty, 1998. Photo by Clark Lunberry

form and detail, a scanning and scrutinizing of its surrogate time and texture- the earthwork as a photographic phenomenon, the earthwork having become its photographs. Like the photographed return of the dead, the photographed Spiral Jetty is, as Roland Barthes described the haunting impact of such an image, "an extended, loaded evidence ... a temporal hallucination, so to speak, a modest, shared hallucination (on the one hand 'it is not there', on the other 'but it has indeed been'): a mad image chafed by reality" (115).

In his own varied investigations, Smithson was fascinated by such prehistoric sites as the Nazca lines of Peru, the scene of a lost legend where mysteriously aligned stones are nearly all that remain of the remote location. Speaking of the famous aerial photographs of this site, Smithson commented in a 1971 interview, a year after the Jetty's completion, that "A photograph acts as a kind of map that tells you where the piece is." He went on to assert that those enigmatic marks in South America "have meaning only because they were photographed from airplanes, at least for our eyes conditioned by the twentieth century" (Smithson, Writings 254), that it's solely from the contracting, framing, transported images that the remote, ancient site can be seen ... can be made to mean at all.

Smithson's analysis of the Nazca lines of Peru might now be effectively redirected towards his own spiraling line in Utah, having itself become a kind of contemporary legend, and loosely linked to a much earlier one: the Native American myth of the enormous whirlpool at the lake's center. For Smithson's earthwork is today 
also seen from above, seen as an image "photographed from airplanes," its "meaning" created as well by the conditioning of our own elevated eyes, its very visibility dependent upon the aerial photographs that were taken prior to its inundation. ${ }^{3}$ Distances to remote Utah (like those to Peru) have been collapsed into flattened formation, creating stilled visions of a disappearance, a death, the image laid out upon a table. The Spiral Jetty is seen now not simply as a photograph, but photographically (the eyes as active adverbs, modifying sight by transforming it) — the mapped land, the place as paper, printed indelibly on the memoried imagination.

Today, more than thirty years after the earthwork's completion, what is the sense and the story to be derived from Smithson's Spiral Jetty, for as he said of the photographed lines in Peru, "What is interesting is how we fail to understand such remote things" (255)? How are our twentieth, and now twenty-first century eyes, to experience and speak of this enigmatic and legendary site, and crucially, to see and understand the "snapshots" of the vanished form, the madness and magic of the images, as Barthes described them, "chafed by reality"? For it is the many photographs that most vividly and accessibly remain of the Spiral Jetty, posthumous renderings that, with the disappearance of the earthwork, have become less like helpful "maps" leading to a location and more like graphic signs directing us nowhere at all. The earthwork's many images point now towards an apparitional object lost, chemical traces signaling into the absence of the site itself. In Smithson's essay entitled the "The Spiral Jetty" (1972), a document that would, like the many photographs, remain as a vestige of his vanished earthwork in Utah, the artist forewarned that "one is liable to see things in maps that are not there" (151).

With or without a map, above or below the water, the Spiral Jetty was from its very beginning difficult to find, to formulate and fix its precise ontological location. In fact, Smithson's earthwork seems from its inception to have been deliberately dislocated by the artist himself into several different manifestations. For along with the many memorable photographs, there is Smithson's essay, the film that was made while the earthwork was being built, and of course, the boulder-filled form in Utah-all identically referred to as "the Spiral Jetty." Each of these Spiral Jetties would seem to refer to the others, but is there not, somewhere, something, upon which all of them must finally settle? Is the object, this object of discourse, never fully grounded anywhere at all (even on the quite literal ground of Utah itself)? Or is it, as Gary Shapiro asserts, that "there is no primary, authentic object ..., no pure Spiral Jetty"? (7). Indeed, in looking for 
the Spiral Jetty, that which may appear most forcefully are the many images, words, and stones colliding into a conceptual scattering of referring forms, its ontological dispersal seeming to have foretold the impending geological one.

And with the earthwork's specific, "pure" presence perhaps never all that certain to begin with, no enduringly solid there there from the start, its abrupt absence or partial absence at the Great Salt Lake is thus rendered even more puzzling or problematic. Is the Spiral Jetty's material disappearance now mattering less or mattering more? When all that remains are the film, the essay, and most compellingly the widely reproduced photographs, what becomes of the object-the submerged earthwork in Utah-to which all the words and images are symbiotically linked? And how is one finally to account for the disappearance of more than 6,000 tons of stone and soil? For one cannot simply walk away from such a massive fact. Perhaps with the photographs as maps, one might return to the site, to find the form by finding its image.

When Robert Smithson completed construction of the Spiral Jetty in the spring of 1970, he knew that his earthwork would one day disappear. Harboring no illusions about its permanence, Smithson had created in Utah a site-specific work that he fully understood would gradually sink into oblivion, the physical form deliberately designed to be destroyed. For Smithson was well aware that the waters of the lake would progressively wear away the earthwork, that the stones of the Spiral Jetty would incrementally erode and eventually vanish, the object conceived as what Craig Owens called a "memento mori of the twentieth century" (206-207). Seeking a broader conception of history from what the artist saw as the shortsightedly art historical, Smithson's focus was upon the more unfathomable expanses of geologic time and its accompanying agents of material decomposition-history deposited in layered sediment, held in a handful of dust. Impermanence and loss were therefore the active ingredients in what the artist referred to as "collaborating with entropy" (256), an interacting with the elements of a site in an indeterminate unfolding. In implementing this complex collaboration-finding its tangible, transient form-Smithson engaged a temporal way of seeing that he frequently described as "dialectical," a term that in the artist's modified sense pointed to the perpetual movement, drift, and decay of all things in time, a pragmatic concept set in deliberate opposition to the more metaphysical, timeless assertions of stasis and stability.

Along with others emerging in the late 1960s such as Michael Heizer, Walter de Maria, Robert Morris, Nancy Holt and Carl Andre, Smithson was clearly a new breed of landscape artist. Exca- 
vating, piling, pouring and scattering, he approached the land as a massive new medium to be measured and marked, his disrupted sites structured and seen in their raw and transforming physicality. Indeed, for Smithson so much depended upon a dump truck, a tractor, a bulldozer, all those "processes of heavy construction hav[ing] a devastating kind of primordial grandeur" (101). Aggressively engaged, the landscape manifested for Smithson a kind of physical, dimensional language, a legible projection that was, as he stated, to be understood as "coextensive with my mind" (Smithson, "Interview" 79). No longer rendered into an ideal, enduring formation, the earth and its thinly encrusted surface were instead a cataclysmic site of "chance and change in the material order of nature" (Smithson, Writings 159). Smithson's was a "dialectical landscape" where the disrupting interactions of time and its tangible surfaces were incrementally altering the varied formations of the land itself-creation and destruction imagined in tandem, ruins rising "in reverse" (72). To place an artwork in the landscape, or to make an earthwork of the landscape-far from the protective spaces of museums and galleries-was to willfully implicate that object in the indeterminate processes of temporality and decay. For an object, any object, existed for Smithson as a "site of time" (105), a contingent form that was understood to be only provisionally present, temporarily containing its otherwise imminent dispersal and loss.

"When a thing is seen through a consciousness of temporality," Smithson wrote, "it is changed into something that is nothing. ... The object gets to be less and less but exists as something clearer" (112). Through his earthworks, non-sites, and mirror-displacements, his photographs and films, as well as his own extraordinary writings, Smithson was developing an intensified mode of seeing that assimilated the object's fragmentation and eventual vanishing into its visuality, which incorporated the inevitable disintegrations of the form into the ontology of the artwork itself. To see the slow movements, to feel the fall into oblivion, giving "passing shape to the unconsolidated views," Smithson was consciously crafting a negative capability, what he described as "a type of 'anti-vision' or negative seeing" that was to paradoxically, ultimately affirm "one's inability to see" (130). Like Rimbaud's poet-as-seer, Smithson included in his own finally blinded perceptions the object's impending dissolution, the scene's disappearance, an awareness of absence encrypted into the site itself. "Space is the remains, or corpse, of time," Smithson wrote, "it has dimensions. 'Objects' are 'sham space', the excrement of thought and language. Once you start seeing objects in a positive or negative way you are on the road to derangement. Objects are phantoms, as false as angels" (122). 
Seeing entropically, seeing the vanishing, Smithson's "consciousness of temporality" was framed and focused upon the slip, the slide, the perishing of that which appeared most solid-the stones eroding, the metals rusting away-the artist glimpsing "something clearer" at the other end of nothing. "You have to realize that the art is really against you," Smithson matter-of-factly noted. "The art is setting out to annihilate your very moorings, it has a way of pulling the ground out from under you.... I'm more interested in showing, with seemingly very stable things, the instability, the elusiveness, the sort of mental disasters that can take place within the whole complex" (Smithson, "Interview" 78).

The annihilation of moorings, the ground pulled "out from under you," but not before the photographers would arrive on the scene. Staging the vanishing and then photographing it, Smithson with his Instamatic 400, or others with their fancier cameras, were almost always there, ready to render a more enduring, stable record of the impending transformations. Like a rubbing from the surface of an inscribed eroding rock, the photograph was to survive and spread as a document of the decline, a captured image of the moment's dispersal. But the question would remain open and unanswered as to what was finally being caught and documented by the many photographs, what the memorable images were really remembering.

With the Spiral Jetty, the immediate material "disaster" that Smithson did not expect to see happen was that, completed in 1970, the earthwork would have virtually vanished by 1972 . Instead of the deliberate, gradual erosion of the object-taking perhaps decades, centuries, millennia-its disappearance would in fact occur, geologically speaking, with dazzling speed. Built with boulders of basalt and compacted mud, using the front loaders, tractors and trucks of major construction, the Spiral Jetty was clearly intended by Smithson to endure at least for the foreseeable future. Interacting with time and the contingencies of the site in a planned, if indeterminate obsolescence, Smithson's earthwork was nonetheless to remain on the Great Salt Lake as a physical emblem of temporal transformation, a monumental mark upon a legible landscape that was to both signal and embody the ongoing event of its vanishing, a slow performance, the "quiet catastrophe" (Smithson, Writings 194) of its own disappearance. Materially enacting a kind of deconstruction (avant la lettre) ${ }^{4}$ of itself-what Smithson would call at the time a "destructuration" (128) - the massive earthwork was to be read as an enduring, yet ephemeral trace, signifying with the one hand, while erasing with the other. Outliving us all, it would persist as a geographic place that one 
might continue to visit, walk upon, and where one might witness firsthand the entropic "physicality of here and now" (187).

Once the earthwork had been completed, photographed and filmed, Smithson stated shortly after the construction that "the Spiral Jetty is physical enough to be able to withstand all these climate changes, yet it's intimately involved with those climate changes and natural disturbances" (298). However, Smithson's controlled “collaboration" with entropy quickly found itself caught up in the uncontrollable indeterminacies of the site itself. Due to the abundant run-off of rain and melting snow from the nearby mountains, the fact that the earthwork appears to have been constructed when the lake itself was unusually low, as well as man-made adjustments to the lake's causeway, the waters surrounding and filling the form abruptly rose above it. Upon the earthwork, the elements quickly accomplished their own destructive design, indifferent to the artist's original agenda. The "climate changes and natural disturbances" of the site had ultimately materialized themselves less as an "intimate" involvement and more as a rapid rampage sweeping over and submerging the stones. What was to have endured as a readable erasure rapidly became an unreadable absence; the crossing out crossing over into nothing at all.

With the earthwork in Utah no longer to be seen, no site on the Great Salt Lake anymore to be visited, the Spiral Jetty quickly became, by default, more dependent than ever upon the other Spiral Jetties, while the ever proliferating photographs continued to be widely published, widely seen, sustaining the earthwork's growing legend. For these vivid images were all that now stood between the object and its own oblivion.

"We live in frameworks and are surrounded by frames of reference," Smithson wrote, "yet nature dismantles them and returns them to a state where they no longer have integrity" (Smithson 375). Within Smithson's own conceptual framework of temporality and entropy-upon his "dialectical landscape"-the artist spoke again and again in his essays and interviews of the dynamic, destructive processes within which he was knowingly working. Aware that the Spiral Jetty's disappearance would come, that its physical "integrity" would finally be breached, the question for Smithson was more aptly when would the vanishing occur, how long would the earthwork survive. For the object itself-like any object-was destined to decline, to lose its definition and return to ruin (having risen as one). And besides, hadn't the Spiral Jetty's varied dispersals- the photographs, the film and the essay-already prefigured the material earthwork's eventual phenomenological loss? 
Eduardo Cadava, evoking the ruin and the intended decline and decay in Smithson's work, notes that "Smithson's ruins-unlike the ruins of romanticism . . .- -seek to remain faithful to the experience of ruin, to the ruin of experience. Rather than reverse the process of ruin, then, the Smithsonian artwork intensifies ruin. It tells us that ruin is irreversible, that there is nothing but ruin" (6). It is the artwork's form and framework-fractured and fragmented-that provisionally affirm the piece's ephemeral content. But this content will survive only as long as its fragile container survives, as long as the materials constituting the object can be made to meaning-fully endure. And for Smithson, among these meanings was certainly, as Cadava suggests, the ephemerality of the object itself, the artwork that was already in ruin and always had been. Described by Smithson as a form of "esthetic consciousness," the artist_-"faithful to the experience of ruin"-sought nothing more than "to know the corroded moments" (107), as the art object forthrightly declined into its own fated disintegration and dispersal. But such a knowledge, of course, finds itself quickly threatened and possibly entangled in its own destructive design, the spread of corrosion finally knowing no bounds. As Smithson acutely observed, "Art brings sight to a halt but that halt has a way of unraveling itself" (129), spiraling out of control.

With the Spiral Jetty, the "unraveling" of the boulder-filled form was to occur far faster than anyone expected. For Smithson would appear to have logistically failed to accurately factor into the earthwork's diachronic design crucial, pragmatic calculations of the geographic site itself, fluctuating levels of the lake, the necessary height of the stones and soil-features that would finally undermine the earthwork's on-going, physical mass and visibility. Smithson, more the artist and less the engineer, seems to have radically misjudged the expedited time frame and the unanticipated geological and meteorological conditions within which the Jetty would be profoundly implicated. As if entropy itself had been abruptly accelerated, the waters of the lake rapidly acted as time's manifest content, the corrosive, concealing agent that quickly covered the earthwork over.

Knowing by 1972 of the Spiral Jetty's inundation, Smithson (as some have suggested) may have intended to return to the Great Salt Lake in order to raise and restore his earthwork, adding soil and stones to elevate the form, to make it once more visible. ${ }^{5}$ Undoubtedly, even though the Spiral Jetty was designed to one day disappear, Smithson would have clearly realized that something had gone awry, failing to fall into ruin according to plan. For it's one thing to speak of ruin, while it's another entirely to find yourself suddenly within one, to feel the waters rising at your feet, to see the vanishing before your eyes. 


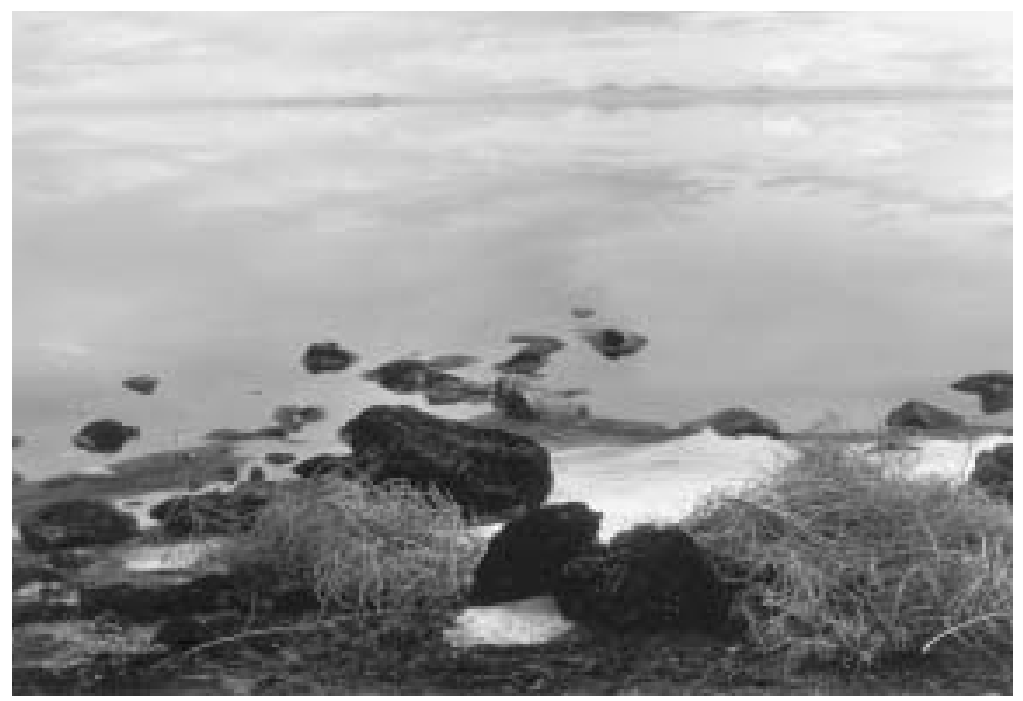

Spiral Jetty,, 1998. Photo by Clark Lunberry

In the end, with the Spiral Jetty submerged and hidden, there would be no time for any drastic interventions by the artist, no time for Smithson to restore his earthwork. For other unexpected, destructive developments would soon determine the direction of events. In 1973 Smithson was killed in an airplane accident as he surveyed and photographed from above a final earthwork in Texas; his sudden, unforeseen death is now routinely referred to as "untimely."

Though there may be irony, poignancy, disappointment in the fact that Smithson's most ambitious and celebrated earthwork would prove itself so rapidly resistant to the artist's intended objectivesthe stones refusing to stay visibly still, to collaborate and signify in the timely manner intended-one way, perhaps, of now approaching the Spiral Jetty would be to imagine Smithson's disappeared earthwork as a kind of time-capsule that was accidentally opened, a ruined object revealing its collected contents but far ahead of any designated date. For if, as Craig Owens described it, Smithson's sitespecific work was to be "an emblem of transience, the ephemerality of all phenomena" and an "allegory" of its own loss (206), then one might conclude that an important aspect of the earthwork's project has been largely accomplished, its legible message expeditiously delivered, read as its own erasure. The vanished Spiral Jetty, precisely because of its vanishing, might now be seen to have confirmed and even fulfilled the artist's own larger, conceptual expectations. Though not occurring according to predetermined schedule, the 
earthwork has still quite literally enacted Smithson's own broad agenda, materializing his understanding of the entropic by dematerializing its representative object.

Of course, it was always Smithson's dialectical frame of reference that had effectively functioned for him as the dominant, temporal dynamic intended to set (and keep) thinking and seeing in motion. In what Robert Hobbs described as Smithson's "art of unresolvable dialectics" (23), this theoretical/perceptual mechanism would seem to have worked for the artist somewhat like a primitive camera that, instead of capturing an image, instantly (instamatically) dissolved it, enframing in its rectangular viewfinder the vanishing and the loss. The artist's own range of phenomenological awareness was thus deliberately positioned by this "viewfinder's" frame to extend beyond the immediate reality of "the-thing-itself" and on toward that object's anticipated decline, its unbracketed absence. Perceiving the object as an entropic event rather than a solid, unalterable form, Smithson was well aware that all of his work, the Spiral Jetty included, was to be only provisionally stabilized and temporarily seen. For nothing, in the larger scheme of things, was to remain unchanged and unchanging and the crucial perception was to see that happening. In a comment that would seem to prefigure the Jetty's own inundation and disappearance, Smithson wrote in 1968 that, "Separate 'things', 'forms', 'objects', 'shapes', etc., with beginnings and endings are mere convenient fictions: there is only an uncertain disintegrating order that transcends the limits of rational separation. The fictions erected are apt to be swamped at any moment" (112).

As already noted, there was from its inception a certain "fictional" quality immanent to the Spiral Jetty, a denial of the object as truly a thing-in-itself, its form willfully dispersed by Smithson into its hybrid manifestations. But thereafter, having also included the "object's" impending material disappearance into the "uncertain disintegrating order" of the earthwork, Smithson's "anti-vision" or "negative seeing" thrust itself beyond the range of his own direct perceptions. Having set the object in motion, dissolved the "convenient fictions" of its solidity and separateness, the artist could no longer carefully control that object's determining trajectory. His reach had deliberately exceeded his manageable grasp, producing what Henri Bergson described of photographic perception as an almost blinding insight, "something which outruns perception itself" (208). With this dialectical extension of sight functioning as a kind of perceptual prosthetic, Smithson had positioned himself to feel the vertiginous fall into the future's entropic collapse, glimpse into vision's own evanescent mise en abyme, where finally, as 
Derrida has noted, "The visibility of the visible cannot, by definition, be seen" (45). Like a moving figure in a nineteenth-century photograph-the child squirming on the mother's lap, a crowd of pedestrians strolling on the sidewalk-the bodies becomes transparent, the forms a blur of dissolving light.

As a physical manifestation of such a destabilized, and destabilizing, form of awareness, the "swamped" Spiral Jetty was thus transformed as well, albeit far faster than intended, into the extended event of its own disappearance, resembling what Smithson spoke of elsewhere as "a site at zero degree, where the material strikes the mind, where absences become apparent." At such a colliding site of change, describing quite aptly what the Spiral Jetty had become, Smithson went on to suggest the even broader, existential implications arising from such a mental/material encounter with absence, the experience depicted as a kind of self-annulling ordeal in which "the disintegrating of space and time seems very apparent. Sort of an end of selfhood . . . the ego vanishes for a while" (194). One sees fleetingly, feelingly—as a form of "esthetic consciousness" - a dispersal of sight and substance clarified in the accretions of particled motion, the form in flux, falling into "something that is nothing."

True, the vanishing act of the Spiral Jetty was not, as circumstances would have it, finally, actually accomplished or manifested by the artist alone, or as the artist might have hoped, but instead it occurred according to factors and forces exceeding (or indifferent to) his own intent. And in the indeterminate process of its transformation, the earthwork's disappearance would seem to have inadvertently revealed a kind of post-object, post-artist art, the ontologically dispersed and now phenomenologically vanished object having broken down into its own uncertain constellation of dematerializing absence. The Spiral Jetty as an allegory of loss, yes, but now as well an allegory that might be read even more richly and complexly, allowing for an expanded awareness of just what that loss might entail: a loss of control, a loss of determining design alongside the unexpected, "untimely" loss of the inundated object.

Once in motion, however, such an awareness of loss cannot necessarily be stopped at the borders of a safe self-consciousness, recollected and rendered in tranquility. For the one observing-the "seer" scrutinizing still the movements and mutations-is ultimately, as Smithson makes clear, entangled and inscribed in the "destructuralized" vision and vanishing, pulled, if only "for a while" (for even this vision is provisional), into the spiral of what seems an almost oceanic dissolution, the sweep of the entropic that eventually captures and contaminates all. "Glutinous light submerged 
vision," as Smithson wrote, "under a wilderness of unassimilated seeing. Scraps of sight accumulated until the eyes were engulfed by scrambled reflections. What was seen reeled off into indecisive zones. The eyes seemed to look. Were they looking? Perhaps. Other eyes were looking" (129). The prosthetic perceptions abruptly, glaringly reflect back upon the one that launched them. Vision itself becomes occluded by the stretching and straining of sight towards its own tethered limit, creating a kind of afterimage of absence imprinted like an undeveloped, undevelopable photographic negative onto the delicate cornea of the eye. Here, the seer is not simply seeing entropically, but the seeing itself has become entropic; the eyes' dissolve, a collapsing vantage onto their own fading vacancy, where finally, as Smithson noted, "To see one's own sight means visible blindness" (40).

Clearly, these entangling perceptions, Smithson's fatal form of "esthetic consciousness," are not to be construed as a variation on the Kantian sublime, the perceiver protectedly and disinterestedly observing/thinking nature's projected grandeur, "provided," as Kant insisted, "we are in a safe place" (120). For the disappearance of the Spiral Jetty is inevitably self-involving, its activated destruction, if truly seen, must be perceived as spreading well beyond its own corroding boundaries, encroaching like a cataract to cover the eye of anyone who would endeavor to examine it. The concealing waters rise and reveal catastrophe all around, ruins within and without. Demonstrating indeed that if an artist chooses to "collaborate with entropy," as Smithson so forthrightly did, no one should be surprised if entropy ends up collaborating with the artist, materializing its movements in indeterminate directions. As Derrida described in his study of an artist in the tentative act of drawing, "Looking at itself seeing, it also sees itself disappear right at the moment when the drawing tries desperately to recapture it. For this cyclops eye sees nothing, nothing but an eye that it thus prevents from seeing anything at all. Seeing the seeing and not the visible, it sees nothing. This seeing eye sees itself blind" (57). Or once more as seen through the primitive camera, imagined, seeing itself, a drawing of light mechanically fixed and framed, the moving form blurs beyond recognition, vanishing into thin air. Like stones dissolving, water washing away, absences made apparent.

Seen, however, through a more contemporary camera-the ones at the Great Salt Lake in 1970, for instance-the Spiral Jetty, instead of blurring or vanishing, has been immobilized into recognition, the dispersed earthwork consolidated as a sharply focused image vividly printed onto paper. Lifted out of duration, what Proust described 
as the "moving universe whirled along by Time" (1009), the many photographs taken at the site achieved a kind of chemical solution to the otherwise entropic dissolution. The click of the camera having caught something of the moment at the Jetty's completion-a chafing, a stained trace, a time-filled shadow-like light held in a hand, a delicate grasping of the fragile vanishing.

As emissaries of the remote object, the developed photographs were then quickly and widely dispersed beyond Utah, beyond 1970 , while simultaneously attesting to some more timeless, placeless state-a surrogate site of stasis and stability that is, paradoxically, always there, always then. And what began as a chemical solution to the object's disappearing effectively became alchemical in its unquestioned conjuring of the site, its transmutation of absence into virtual presence. The monumental Spiral Jetty, seen from above, was-as a matter of photographic fact-rapidly contracted, transported and transformed into its two-dimensional image, suggesting in its steadied dimensions that more manageable, discrete genre of the still life. Or perhaps more aptly, the French nature morte, the earthwork mimetically preserved for all to see, forever to see, unchanged and unchanging, dead or alive.

Craig Owens asserted of the photographing of such site-specific works as the Spiral Jetty that the "photography represents our desire to fix the transitory, the ephemeral, in a stable and stabilizing image. In [these] photographs ... insofar as they self-consciously preserve that which threatens to disappear, that desire becomes the subject of the image" (207). And as depictions of just such a desire, the ever-proliferating photographs of the Spiral Jetty have over the years become increasingly prominent in sustaining the discourse, sustaining the seeing of the earthwork; the affective images as crucial, enabling components in the creation of the Jetty's rising legend. Indeed, the photographs have gradually taken on a life of their own, and like the rising waters of the lake, the images have in effect inundated the earthwork in Utah, covering it, papering it over as a flat simulacrum of itself.

Much as Smithson had argued that Cézanne and his contemporaries had been "forced out of their studio by the photograph" only to be abruptly returned by what he saw, unorthodoxly, as the "empty formalism" (188) of Cubism, one might now contend that a related, but reversed process of recuperation happened with Smithson (and his contemporaries) and the Spiral Jetty. ${ }^{6}$ If Cézanne had been "forced out" by photography, made to scrutinize more immediately his beloved Mont Sainte Victoire, Smithson had in a sense been forced back in from Utah by the same demanding medium. For over time, and in the hands of others, the photographs of the earthwork have 
efficiently, often surreptitiously served multiple purposes, all of them offering a semblance of control over an event that would otherwise appear to have entirely exceeded such control—a vision regained, a ruin restored. And the earthwork's photographs might perhaps also be seen as yet another variant of an insistent, "empty formalism," like the one that had driven Cézanne back into his studio and that years later lifted the Spiral Jetty out and away from the Great Salt Lake. The images of the earthwork insinuated themselves into its vanishing, into its initially scattered ontology, only to then finally confine it squarely onto the printed page.

If an important part of the Spiral Jetty's ambitious initial agenda had been to deny the fictions of the "thing-in-itself" by manifesting its own dispersion (into multiple forms) and its own disappearance (as an entropic event), then its widely seen photographs may now be understood to have retrospectively, self-servingly subverted the artist's initial intentions. For the images, instead of documenting a vanishing event, would seem to have posthumously restored the very fiction that was supposed to have been challenged and dispelled, returning the thing-to-itself by focusing the fading object into a steadied, viewable image; the dialectic abruptly denied, entropy apparently avoided. And though the photographs of the Spiral Jetty may have been intended as but one component of a larger kind of dispersed "text" - the boulder-filled form, the film, the essay, etc.-it can now be seen, however, that the effective, unconscious impact of the images would seem to have been, not to further disperse the object (or even to simply assist in archivally remembering it), but rather to forcefully reign it in. The Jetty's projected plurality has been wrested into the settled singularity of its photographs, "steal[ing] away," as Smithson described such photographs "the spirit of the work" (251).

Published and widely seen, the Spiral Jetty quite quickly became an iconic image, became its iconic images, spread thin in books, magazines, and journals, attesting now to its phantasmatic place upon a printed lake, its sustained presence within its own enduring legend. The images of the earthwork discretely transformed themselves into what Roland Barthes had diagnosed of the photograph as a "shared hallucination" (115), dissolving the "three-dimensional object into a two-dimensional effigy" (88). And like mirrors facing one another and reflecting infinitely, the photographs of the Spiral Jetty appear to have become almost entirely self-sustaining, the blur of mechanical reproduction seeming to have long ago erased any trace of the originally photographed object. It's as if, in 1970, when first absorbing the earthwork's reflected light, the cameras had, corrosively, begun to absorb its physical form as well, the mechanical 
eye wearing away the stones themselves, like water chafing at the edge of the object.

Walter Benjamin famously described the art work's loss of aura through the proliferation of its mechanically reproduced photographs, the denial of that object's "presence in time and space, its unique existence at the place where it happens to be" (220). What appears, however, to have occurred in the case of the Spiral Jetty suggests a curious rewriting of his formula in which the "time and space" of the earthwork have indeed been abrogated, but the earthwork's aura has nonetheless found alternative outlets for its persuasive emanation-demonstrating perhaps that auras, the undying need for the aura, is apparently not so easily dismissed. For with the Spiral Jetty, it is precisely the photographs that would seem, not to have destroyed any aura, but to have formed and perpetuated one, the images creating and spreading the earthwork's "cult value" (224) and establishing its "distance however close it may be" (222). And as a consequence of the photographs' very effectiveness, the boulder-filled form out in distant Utah appears to have become increasingly incidental, as if the contracting dimensions of the photographs had finally contracted the massive object itself into a dislocated oblivion. Barely noticed and rarely acknowledged, the stones of the Spiral Jetty have faded unceremoniously from view and been largely forgotten. And though this may not entail the loss of the "authentic," "original" earthwork, for that loss was included by Smithson himself in the Spiral Jetty's initially dispersed design, there is nonetheless the loss of something significant, something of valuea loss that still must be somehow accounted for.

The Spiral Jetty's photographs as "maps," once leading to a location, would seem no longer to lead anywhere at all but self-referentially back to themselves-not to the stones or the essay or the film, but instead, the images always returning, to their own mechanically printed, aura-filled reflections. And these reflections, as Craig Owens attested, perhaps finally reveal their subject to be not the Spiral Jetty at all, but instead that of desire itself-the desire to preserve the ephemeral and the fallen, the desire to repress and reject the object's immanent transience and loss, seeing that which one wishes to see rather than that which remains to be seen. For that which remains of Smithson's Spiral Jetty is, like a mortal body vanishing before your eyes, next to nothing at all. The tons of stone and soil have been rendered either redundant or obsolete, dissolved beneath the unbearable lightness of the earthwork's proliferating images, and Utah doesn't matter anymore.

The Spiral Jetty is printed vividly upon the page, fixed in its own image, like a mirage cast clearly onto the papered horizon, pub- 
lished, preserved, and protected for everyone to envision. The earthwork thus affirms itself in its own imaged endurance, its own resistance to vanishing, with the photographs as "shared hallucination," affirming something of the same for those of us who now so desiringly see.

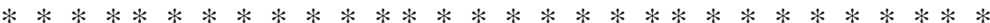

"Let photography quickly enrich the traveller's album, and restore to his eyes the precision his memory may lack. . . . Let it save crumbling ruins from oblivion, books, engravings, and manuscripts, the prey of time, all those precious things, vowed to dissolution, which crave a place in the archives of our memories; in all these things, photography will deserve our thanks and applause. But if once it be allowed to impinge on the sphere of the intangible and the imaginary, on anything that has value solely because man adds something to it from his soul, then woe betide us!"

—Charles Baudelaire, "The Salon of 1859"

"For me the world is a museum. Photography makes nature obsolete."

-Robert Smithson

Invitation to the Voyage: In spite of its notable disappearance at the Great Salt Lake, the Spiral Jetty's stature, like Smithson's as well, seems only to have grown, both of them (regardless of their shared, untimely vanishings) becoming at some point almost larger than life, rising in reverse into legend. Indeed, Smithson was long ago inducted into many of the institutions that he had forcefully challenged and resisted, with his Spiral Jetty soon emerging (as if from out of water) as an emblem of itself, its familiar photographs now placed within the orderly art historical narratives of an era. And the widely reproduced images of the earthwork would seem to have dutifully sustained the vanished object, recalling Baudelaire's early prescription for (and indictment of) photography to restore to the eyes that which has disappeared, to save a crumbling ruin, "all those precious things, vowed to dissolution, which crave a place in the archives of our memories" (297). 
Yet of all that has been written over the years about Smithson's celebrated earthwork, it is both striking and strange how rarely the geological fact of its disappearance in Utah has been discussed at all, how little has been made of the massive object's vanishing from view. For again and again, from shortly after its inundation in the early 1970s until today, those researching and writing about the earthwork have generally presented the Spiral Jetty as if it were still out there, still very much visible at the Great Salt Lake if only one were to go. ${ }^{7}$ Arguments have been presented, insights uncovered, assorted books and articles published on Smithson's earthwork, with nearly all of them obligating the object to stay in place, to continue looking just as it did when it was completed, just as it does in the photographs-like a body unchanged and unchanging, the past and the present congealing into a singular, ageless assertion. Recalling Smithson's own description of a "criticism dependent on rational illusion" (112), so much of the Jetty's commentary has depended upon an etherealization of the remote object, a dematerialization of the immense form into its familiar photographs. For like pictures projected from a Proustian magic lantern, the images of the earthwork-without our having to leave our rooms-have been cast as a two-dimensional landscape (or dreamscape), creating a lighted illusion appearing on the surface of a vacant lake. The photographs of the Spiral Jetty have thus permitted all of us to see that which we have wished to see, needed to see-the object enduring, an icon intact, a specific site for our own groundless imaginings. The photographs thus remain as utterly believable substitutes, authentic apparitions, all that has been needed to restore to our eager eyes the vanished earthwork, raise the form once and for all from out of the waters that both reflect and conceal the Spiral Jetty, affirm and deny its place upon the lake.

The manner in which the Spiral Jetty's disappearance has been dealt with over the years by so many would seem to demonstrate nonetheless a remarkable omission, a curious collective forgetting, that a physical phenomenon so widely (if vaguely) known could be almost entirely ignored, that the inundation and vanishing of tons of stone and soil could be so readily dismissed as being of little consequence. For the earthwork's disappearance has in fact been well known from the beginning, with nearly everyone writing on the Jetty seeming obliged at some point to, at the very least, mention it. Very often, grudgingly, brief reference to what has happened to the earthwork in Utah will be made, noting the rise of the lake and the subsequent inundation of the form. But such comments are generally relegated to parenthetical asides or buried footnotes, present- 
ing the development as merely an unfortunate or incidental detail with little real bearing on the Spiral Jetty itself. Also, readers are occasionally reminded that at any rate, prior to his death Smithson was aware of the problem and that he may have intended to raise the earthwork (as though the intention itself had virtually accomplished the act). While more recent writers have often seemed to pass over the earthwork's disappearance almost entirely, arguing that since the Spiral Jetty, as a kind of post-structural text, was from its beginning an artwork with multiple referents-a film, an essay, photographs, maps, etc.,- - the covering over of the actual stones by the Great Salt Lake matters less than one might think, for the object has been, regardless, always elsewhere anyway. ${ }^{8}$

While consistently-no matter who was doing the writing or how the Jetty was being discussed-the photographs have always been textually present, commandingly accompanying the varied arguments and ideas. Indeed, the photographic medium has become an increasingly enabling element of the earthwork's message, the "picture worth more than a thousand words," more than the 6,000 tons of stone and soil. Like graphic notes toward a sufficient fiction, the images have offered the ocular proof of the earthwork's endurance, confirmed the object-as-image, ready-to-hand, a remoteness dispatched into immediate location. In the essays, in the books, we can point to the object in the photograph, feeling remarkably certain of what is being seen and discussed, the known absence almost effortlessly, unthinkingly transformed into the believed presence of the earthwork. And though the photographs of the Spiral Jetty may have perhaps begun quite practically as straightforward illustrations in an essay, recorded documents or component parts of a larger event, they would appear over time to have been transmuted by our own often unexamined, perhaps unexaminable, needs into something far more mystifying and intangible, the images illusively taking on a life of their own as we hold them in our hands, carefully examining their spectral dimensions.

But still, in spite of the clarity of our own printed perceptions, there is the recollection of an oversight, the suspicion of a self-serving neglect, the return of the repressed. The lake, that place, that thing out there in Utah-the geographic location of a site-specific absence. And further, the feeling that if the vanished Spiral Jetty and its visible images have indeed come to constitute a kind of collective hallucination, Baudelaire's craved place-projecting a photographic presence upon a phenomenological vacancy-then in continuing to think about Smithson's earthwork (in all its manifestations), perhaps we should examine how such insistent apparitions may have first arisen, how something so iridescent as the object-as- 
image has been sustained and perpetuated for so long, and how writers and observers have taken the photographs, applying them strategically to fashion a kind of convincing fantasy that we have then so rapidly subscribed to, adding the images "to the archives of our memories." Then, looking into our own desiring eyes, we may begin to wonder if the issue of seeing itself-the Spiral Jetty's appearance or disappearance, its ontology as an object or an image-has finally proven itself to be far more intricate and involved than initially imagined. If Henri Bergson is to be believed and "perception is only a true hallucination" (239), then where would we have to go, what would we have to do to locate the precise vanishing point of Smithson's Spiral Jetty, to arrive at the site of our own craving, to see the source of our own hallucination?

Along with an early, influential analysis of the Spiral Jetty, the art historian and critic Rosalind Krauss begins and ends her book, Passages in Modern Sculpture (1977), with two nearly full-page, black-andwhite photographs of Smithson's earthwork as it appeared at its completion in April, 1970. In her book, Krauss argues that modern sculpture crucially distinguishes itself from that of earlier eras by the manner in which it foregrounds itself as a temporal medium. Materially enduring in time and physically experienced in time, the sculptural forms embrace a certain "theatricality" (in opposition to more static aspirations of "presentness," or even "grace") by "merging the temporal experience of sculpture with real time" (203). Smithson's Spiral Jetty is prominently presented by Krauss as an important example of sculpture as such a "temporal event," its photographs carefully placed within the text to corroborate her theoretical position.

Aside from the customary captions, the two photographs of the Jetty are never spoken of directly by the author as photographs, nor are there any specific references to that which appears within them; instead the images are simply there on the page, intended, apparently, to speak largely for themselves, while indirectly illustrating the adjacent arguments being made. What is it, however, that is actually being illustrated in these two arresting images and of what do the photographs most compellingly speak? What might we learn by looking carefully at how Krauss has used these photographs as discretely signifying features of her text, and examining her use of the images as an important, prototypical example of how so many other writers would use various photographs of the Spiral Jetty for years to come? And finally, with the photographic medium understood as being part of a larger, more complex message, a neglected or repressed element of the earthwork's ontology, how have the 
photographs of the Spiral Jetty come to help constitute our own immediate convictions about Smithson's earthwork, convictions that would now seem so persuasively to sustain the vanished object?

The first photograph, accompanying Krauss's introduction, was taken from above, from an airplane flying over the lake, and it presents a tightly cropped, crisp, clear image of the Jetty below. Specific shapes and sizes of the stones can be discerned in the photograph and the translucent waters of the lake are rippling and glistening. The even, midday light, the panoramic elevation and angle, and the sharp focus of the photograph contribute strongly to the mimetic persuasiveness of this image, the visual sense of a straightforward transcription of an observed reality. Indeed, in looking at this familiar photograph of the earthwork (one which would become a standardly used image in the future) there is the quiet assurance that we are seeing on the page an imprint of the real- the Spiral Jetty as it was, as it is, now timelessly there on the lake, in the book.

On the other hand, the second photograph of the Spiral Jetty appears quite differently from the first and is found in the final chapter, near the very end of Krauss' book. This image, also from 1970 and in black and white, ${ }^{10}$ was taken from the opposite direction of the first, with the photographer positioned on the tall hill behind the earthwork, once again giving a similarly elevated perspective onto the Spiral Jetty below. Unlike the opening photograph, however, this image would appear to have been taken almost directly into the sunlight itself, washing out much of the specific, crisp detail seen in the first image. Here, the tonal delineation of the stones and the water is vividly heightened, producing a far more starkly contrasting representation of the earthwork. In fact, the stones of the Jetty, with their individual characteristics largely lost, have taken on the ink-like blackness of a boldly drawn line, while the light upon the lake is so fully bleached out that it appears visually absorbed, the water merging with the whiteness of the page upon which the photograph has been printed. The striking effect created by this image presents the Spiral Jetty as if it were simultaneously grounded in the graphic, while rising into something far more ghostly.

Also seen in this second photograph, just off shore at the start of the earthwork, very small but unmistakable, is the sharp silhouette of Robert Smithson himself cast against the white water of the lake. Standing in profile, a knee thrust forward as though the photographer had caught him in motion, he seems to be walking in place upon the stones of his own Spiral Jetty.

Unlike the first image, this final photograph creates a compelling, nonnaturalistic effect through its bold delineations of water and stone, light and darkness. The visual impact of the image quite 
differently captivates the eye, seeming to offer not an imprint of the real, but instead an accentuation of it. Something more than mimetic, something other than real, the photographed Jetty appears in the book almost ethereal and otherworldly, yet still graphically fixed and framed. Like the unmoving body of the artist seen walking on the printed page, the stones of the vanished earthwork rise out of the water and are lifted out of time.

In her introduction and directly adjacent to that first, more naturalistic photograph of the Spiral Jetty, Rosalind Krauss outlines the central issue of her book:

\begin{abstract}
The underlying premise of the following study of modern sculpture is that, even in a spatial art, space and time cannot be separated for purposes of analysis. Into any spatial organization there will be folded an implicit statement about the nature of temporal experience. The history of modern sculpture is incomplete without discussion of the temporal consequences of a particular arrangement of form.... One of the striking aspects of modern sculpture is the way in which it manifests its makers' growing awareness that sculpture is a medium peculiarly located at the juncture between stillness and motion, time arrested and time passing. (4-5)
\end{abstract}

Published in 1977, after the Spiral Jetty had already been underwater and unseeable for several years, Krauss' important analysis of modern sculpture, with the Spiral Jetty as one of her primary examples, strikingly demonstrates the puzzling disconnect that would characterize so much of the commentary on Smithson's earthwork in the years ahead. For reasons unexplained, Krauss does not mention in any way what she must have known at the time her book was published, ${ }^{11}$ that the Spiral Jetty had indeed vanished beneath the risen waters of the Great Salt Lake. In addition, the formal layout of Krauss' book, with its carefully placed photographs intended to illustrate and substantiate the adjacent commentary, would also very much typify the manner in which the photographs of the Jetty would be textually applied by so many others in the future-the earthwork continuing to be discussed and seen as if it were still physically visible in Utah, while relying upon the photographs to assert a more enduring presence, to act as a kind of "double" for the otherwise vanished object.

It is, however, remarkable and perhaps telling that Krauss would have chosen to use as a crucial instance of modern sculpture's unique "temporal" definition the still photographs of an earthwork that had in fact, with time, disappeared. Or rather, it seems a curious oversight that the temporal, phenomenological evidence of the Jetty's own mortal duration would not have been noted 
by her at all, considering Krauss' insightful claim that in looking at such sculpture, "space and time cannot be separated for purposes of analysis" and that such an attempt is "incomplete without discussion of the temporal consequences of a particular arrangement of form" (4). For it does seem fair then to ask, what about the "particular arrangement" of the Spiral Jetty and its form? And furthermore, if what distinguishes modern sculpture is its location at the "juncture between ... time arrested and time passing," then wouldn't the Jetty's own quite literal temporal passing seem to be worthy of some kind of acknowledgement, suggesting in itself some perhaps unexpected significance?

Indeed it could be argued that, inadvertently, Krauss' choice of the Spiral Jetty as a representative object of an embodied temporality, a sculpture very much at the juncture of time's active passing, was even more appropriate than she herself was prepared to acknowledge - a material earthwork exceeding its own theoretical analysis precisely by fulfilling that analysis, by so precipitously sinking into time. If we are now "forced increasingly to speak of time" (4) in any analysis of modern sculpture, then it would seem that Krauss may have stopped too soon (as so many others would as well in the years ahead), not speaking enough, letting the photographs of the earthwork speak for her of another kind of time, a photographic time that, in a sense, is no time at all.

Krauss sustains her final discussion of the Spiral Jetty around the second photograph. Here, she forcefully, movingly, concludes with a renewed emphasis upon temporality, a description of the physical act of "passage" upon the material earthwork itself, and the necessary "humility" required in the reconciliation of time and its lived experience. As already noted, this final photograph conveys a distinctly different impression from the opening image, having lost much of its mimetic vividness while taking on a far more elusive, evocative quality. However, the commentary adjacent to this quite stunning photograph once again, as at the beginning of the book, would seem to require a (hypothetical) voyage to an earthwork that never changes. For Krauss writes:

The Spiral Jetty is physically meant to be entered. One can only see the work by moving along it in narrowing arcs toward its terminus. As a spiral this configuration does have a center which we as spectators can actually occupy. Yet the experience of the work is one of continually being decentered within the great expanse of lake and sky. ... Smithson creates an image of our psychological response to time and of the way we are determined to control it by the creation of historical fantasies. But the Spiral Jetty attempts to supplant historical formulas with the experience of a 
moment-to-moment passage through space and time.... In every case the image of passage serves to place both viewer and artist before the work, and the world, in an attitude of primary humility in order to encounter the deep reciprocity between himself and it. (281)

As a conclusion to her book, these very words literally wrap around that last, more etherealized photograph of the Spiral Jetty. And though the adjacent writing makes no direct reference to the attached illustration, the language would seem nonetheless to echo into the image, the image into the language. For the photograph is presented as a kind of tacit affirmation, a spectral confirmation of the Spiral Jetty, a snapshot from a timeless voyage to the site itself, the earthwork visible, above water, as if floating permanently there on the page.

Once more, however, we may be reminded of Utah, memory's (repressed) return of the stones of the Spiral Jetty-the object photographed, the object discussed-that have disappeared beneath the Great Salt Lake. We might recall as well Smithson's own expectation of visitors actually, unhypothetically traveling to the remote site, "covering distances" (192), seeing it for themselves. ${ }^{12}$ For how are we to respond to an analysis that seems to have created, in the very elegance of its argument, its own "historical fantas[y]," a fantasy that forgets the earthwork's geographic location, denies its material disappearance. And hasn't the argument itself become yet another instance of a static historical formula, "determined to control" the disappearance of the Spiral Jetty by enlisting the photographs to affirm its endurance, and thus making possible the continued endurance of the argument itself? Indeed it appears that the photograph and the language are here stealthily colluding on the page in a symbiosis of mutually sustaining assertion, that this photograph of the Jetty, as a quiet corroboration of the writing, is acting as a necessary surrogate of visibility and presence, a free-floating signifier without a signified, an image representing an object that, far from floating, has indeed long ago sunk.

Krauss continues her discussion of the Spiral Jetty with a vivid description of the disorienting physicality brought about by the experience of actually visiting the Jetty, entering the earthwork, and "of continually being decentered within the great expanse of lake and sky" (282). Here, however, with implications not limited to the breadth of her own observations, Krauss' acute analysis of her own psychic, somatic involvement with the earthwork would in fact seem only to be magnified further, even more poignantly confirmed, by the quick disappearance of the Jetty. For once again, and more forcefully than seems to have been intended, with the Jetty's vanishing, there is immediately an added, unexpected dimension to what would be the 
"disorienting" experience of trying to verifiably visit Smithson's earthwork. The boulder-filled form that may have initially (and very briefly) provided a kind of tentative ground for "passage," a geographic site for a "decenter[ing] within the great expanse of lake and sky," has itself been swallowed up by the inundation, leaving the expanse of lake and sky even more vastly encompassing than Krauss was willing to allow. And with the earthwork underwater, our own centering is now placed in further jeopardy, perhaps requiring of us an even greater degree of "humility" than Krauss herself had counseled. The loss of the material earthwork now leaves the humbled eyes of the viewer more disoriented than before, threatening a more troubling, visceral involvement with the earthwork's vanishing. But as Smithson wrote, perhaps anticipating some of the eventual analysis of his work, "The rational critic of art cannot risk this abandonment into 'oceanic' undifferentiation, he can only deal with the limits that come after this plunge into a world of non-containment" (102).

Finally, contributing further to the notable disconnect between the material Spiral Jetty and its known entropic outcome-the imaginary voyage versus the very real visit-is Krauss' remarkable assertion that we "can only see the work by moving along its narrowing arcs" (281), attempting to "actually occupy" the spiral's illusive center. Yet knowing what we know, and what she must have knownseeing what cannot be seen-, how are the distances between the eye and the mind to be traveled, the real and the imagined to be reconciled? For what is it that remains to be either seen or occupied of the Spiral Jetty if there is, actually, no longer anything out there to "see" or "move along," no solid stones upon which to stand? Assuming that we were to visit the Spiral Jetty-either in 1977 or todaytaking up Smithson's invitation to travel to Utah in order to locate the earthwork, the Jetty's disappearance beneath the risen waters of the lake would seem to quite literally strand us on its dry shores faced with the uncertain predicament of what he spoke of elsewhere as a "a very ponderous, weighty absence" (193), our eyes seeing virtually nothing, a passage now onto nowhere.

Or rather, once out there, seeing nothing and passing nowhere but into the picture itself, that ethereal and unearthly, site-specific photograph of the now siteless Spiral Jetty, the dislocated earthwork transposed onto the literal landscape of our imagination and us scanning the reflecting waters in search of its archived image. As Smithson described the photographic effect of seeing such a vanishing view, "The photograph is a way of focusing on the site. Perhaps ever since the invention of the photograph we have seen the world through photographs and not the other way around" (192). The vivid mirage on the horizon suddenly appears as an inspired 
illusion of vision and visibility. For this is a photograph that-like Alice through the looking glass-we can now enter and "occupy," and that in turn, with time, has come to occupy those of us who look upon it. We see, as many have described it, in the shape of our desires and, astonishingly, the shape turns out to be a spiral, the photographed form extending out into the evanescent waters. And like Smithson himself temporally suspended on the page, forever walking upon the stones, our place in the picture may finally be coming into focus, the ground beneath our feet, the sight before our eyes about to materialize, about to be seen.

$* * * * * * * * * * * * * * * * * * * * * * * * * * * * * * * *$

"The quality of nothing hath not such need to hide itself. Let's see-Come, if it be nothing I shall not need spectacles.”

—Gloucester in King Lear

"I had to travel, to divert the enchantments assembled over my head."

-Arthur Rimbaud, A Season in Hell

"Is not this rather the place where one finishes vanishing?"

—Samuel Beckett, The Unnamable

Finally Arriving: When I drove to Utah's Great Salt Lake in early 1998 to look for the Spiral Jetty, I wasn't at all sure at the time what I was going to find once I got there. Like everyone else, I knew that the remote earthwork had been underwater and unseeable almost since its completion in 1970, but word had spread that sometime in the mid-1990s, due to a lowering of the lake from limited surrounding rainfall, the Jetty had unexpectedly resurfaced and was again visible. After more than twenty years hidden beneath the water, Smithson's most celebrated earthwork could perhaps once more be seen, actually entered and walked upon-just as Rosalind Krauss had earlier described it, and just as I had always pictured it. It seemed, therefore, the right time to go, to make the long drive, to try and locate the earthwork spiraling out into the lake; after all of these years of looking at the photographs, to see for myself what I'd always seen, already seen, and certainly once arriving, hoped to 
see again. Of course, like the tourist (that I was) traveling to visit a renowned monument, I took my camera along with me, intending to photograph whatever was finally found.

I traveled for two days, crossing half the country, before arriving in Salt Lake City. The drive from there proved to be long and difficult, the exact site of the earthwork even more distant and hard to locate than initially imagined or described. Soon off any major highways and eventually driving across open pasture land on dusty, rocky roads, I followed vague directions obtained on the internet, traveling slowly for a couple of hours, and feeling far from certain about the progress I was making. In fact, by this time (and for the next hour or so), I'd lost all sight of the enormous lake itself, seeing only the grassy hills that seemed to stretch on forever. As I drove, the renowned remoteness of the landscape seemed increasingly, palpably real, the Spiral Jetty's often described "inaccessibility" more and more likely. For I wondered anxiously if I'd ever get there at all, if I was even going in the right direction, if the car would hold up on the terrible roads, and, in the back of my mind, whether the Spiral Jetty, once I arrived, would still be visible at all ... if I'd get there in time.

Eventually, exhaustingly, after several hours of difficult driving, I left the car behind once the road had withered to nothing more than a rocky, eroded cattle trail, and I hiked the remaining distance, at last locating, according to the instructions, the site of the earthwork. It was then that I discovered what I'd feared (but somehow half expected): the waters of the Great Salt Lake had indeed risen again and the Spiral Jetty had, once more, vanished. All that remained to be seen at the site of the legendary earthwork was a scattering of small ice and salt-encrusted stones, a dozen or so, barely appearing out of the water and off from the shore.

For several minutes I stood looking, thinking, realizing what had happened. Gazing out onto the lake, there were no spirals to be seen, no earthwork for me to walk upon. Yet, remarkably, my reaction at the time was not really one of regret or disappointment; surprised, a bit bewildered, feeling vaguely foolish perhaps, but happy nonetheless to be there, and relieved to have finally reached my difficult destination. And regardless of what was not there, the expansive site itself-the lake, the land, the sky-was still breathtakingly beautiful, the silence and isolation of the place so powerfully present; it seemed as though I'd arrived at the very heart of the earthwork's imagined remoteness, accessed something of the otherwise inaccessible. It felt as well as if, geographically, I'd reached the site of a vanished ruin, the place of a memory, the source of an image, tantalizingly near, just off shore, abruptly in the presence of an almost tangible absence. I recalled Smithson's description when 


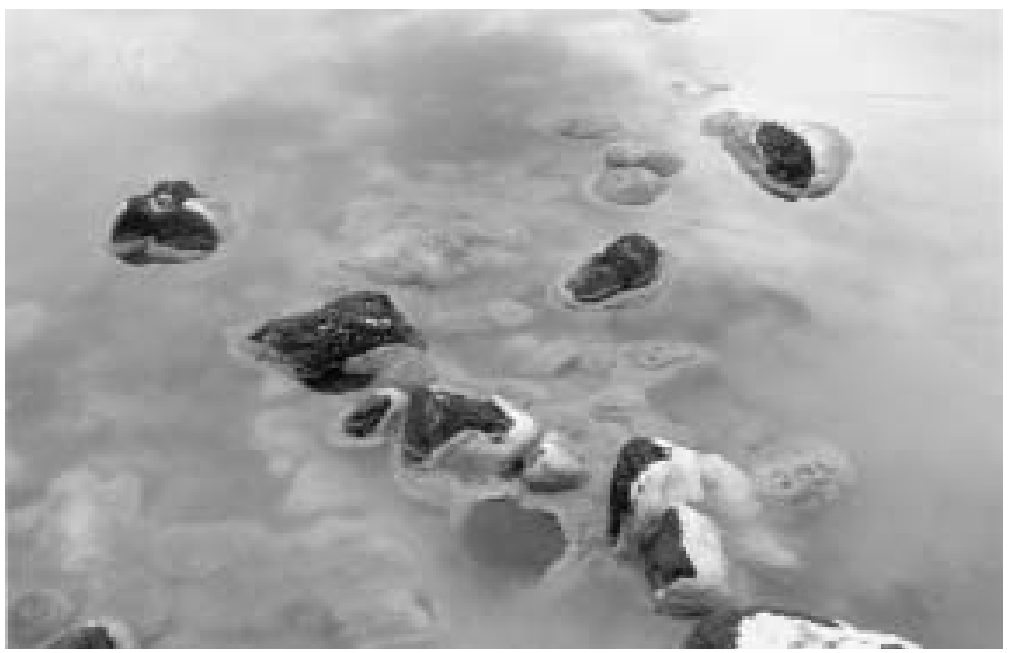

Spiral Jetty,, 1998. Photo by Clark Lunberry

he first arrived at the same empty location and decided that it would be the place to build his earthwork:

As I looked at the site, it reverberated out to the horizons only to suggest an immobile cyclone while flickering light made the entire landscape appear to quake. A dormant earthquake spread into the flutter-rotary that enclosed itself in an immense roundness. From that gyrating space emerged the possibility of the Spiral Jetty. No ideas, no concepts, no systems, no structures, no abstractions could hold themselves together in the actuality of that evidence. My dialectics of site and non-site whirled into an indeterminate state, where solid and liquid lost themselves in each other. It was as if the mainland oscillated with waves and pulsations, and the lake remained rock still .... Matter collapsing into the lake mirrored in the shape of a spiral. No sense wondering about classifications and categories, there were none. (146)

I walked along the shores of the lake looking for further evidence of the Spiral Jetty but finding little or nothing to materially remind me of the earthwork that had once stretched hundreds of feet out from those shores, shaped by tons of transported stone and soil. No sense searching for an earthwork, there was none. Instead there were only bits of broken asphalt at the edge of the lake upon which the dump trucks had presumably driven, while off shore, the glassy surface of the vast expanse of water was unbelievably quiet and calm, mirroring with an almost eerie perfection the clouds in the sky, the mountains on the horizon, and the handful of scattered stones appearing from off the surface of the lake- the only solid and tangible trace of the earthwork itself. Later, I climbed the adjacent tall hill, the one from which famil- 
iar photographs of the Spiral Jetty had been taken, thinking that the increased elevation might allow me to see more of the earthwork's stones beneath the shallow, translucent waters. But even from above, I could make out nothing further of the Jetty than I had down below.

In spite of the Spiral Jetty's notable absence that day, I stayed for many hours at the site, climbing the hills, walking the shores, always looking, perhaps thinking, hoping that from somewhere, from some angle or elevation something, something more, might finally appear. If only I'd look hard enough, long enough, my determined, desiring eyes might finally conjure something substantial from out of the still waters. Like a photograph developing before me, the liquid lake itself suddenly seemed like a photographer's tray of chemical fluids. Might the Spiral Jetty once again come into sight, rematerializing the memory? Yet no matter how hard I tried, the mirroring lake offered me nothing much more to look at but, looking straight down from the shore, reflections of myself looking. My own (scopic) drive to Utahthe distances covered, the remote site finally located-exposing, overexposing, ultimately, most glaringly perhaps, my own desire to see what would not show itself and could not be seen.

Eventually I got out my camera and began to take pictures of the site. I carefully photographed those few remaining stones, the unbelievably still lake (a lake that is essentially a dead sea, a circumscribed oceanic), and the distant watery and mountainous horizon. Also, again, I climbed the adjacent hill in order to get that more elevated perspective that had been seen so often in those earlier photographs. Looking through the viewfinder of the camera, perhaps I imagined that the developed images might find a view of the Spiral Jetty that my own naked eyes couldn't, Benjamin's “optical unconscious" uncovering Barthes' "infra-knowledge" of the otherwise absent earthwork, like an x-ray entering into the lake and retrieving the memoried object. And yet as I was taking the pictures, I couldn't help feeling at times, almost foolishly, as if I was photographing a photograph, a ruined, faded image, an emptied frame, taking vacant snapshots, willful remembrances of things past, and expecting something from that to be captured by the camera. ${ }^{13}$

In spite of the striking absence before me and the failure to see what I'd come so far to see, the longer I stayed at the lake-walking, thinking, looking through my camera-I began to sense the dialectics of my own perception quietly colliding with the site itself, the mentally archived images of the 1970 Spiral Jetty chafing against what Smithson had described as "the actuality of that evidence" before my more immediate eyes. Looking out and not seeing nothing exactly, but something stirring, something uncertain in the empty picture before me, a perceptual event, punctum-like, Barthes' "subtle 


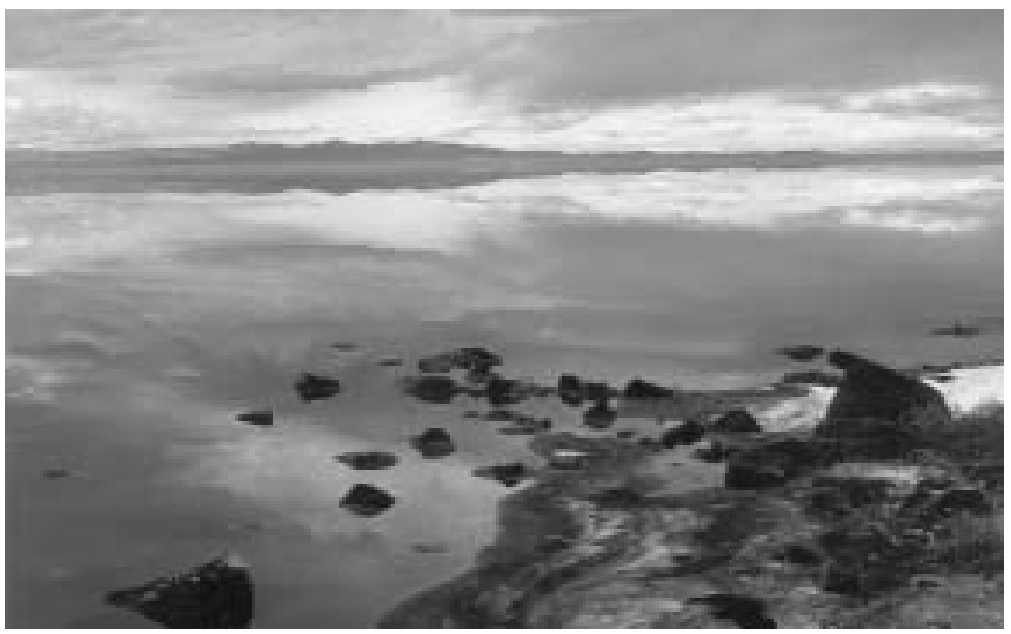

Spiral Jetty,, 1998. Photo by Clark Lunberry

beyond - as if the image launched desire beyond what it permits us to see" (59), inciting a premonition of imminent appearance about to be seen, about to "outrun," as Bergson had said, "perception itself" (208). It was as if, in approaching the earthwork's image - the image like a receding mirage-I was on the verge of entering into an apparition, into the very heart of the shared hallucination of the Spiral Jetty itself. Look what thy camera cannot contain, commit to these waste blanks ... ${ }^{14}$ Photographing the photographs, the camera's shutter eclipsing the eye, and me seeing over and over the image and its absence, the picture taken again and again and again, as many times as my blinking eyes could see it.

I stayed that day until my camera ran out of film and then I left. It was getting dark and it was time to go. I couldn't see anything anymore.

"Living beings dwell in their expectations, rather than in their senses." George Santayana wrote (in a passage Smithson frequently quoted), "If they are ever to see what they see, they must first in a manner stop living; they must suspend the will, as Schopenhauer put it, they must photograph the idea that is flying past, veiled in its very swiftness" (381).

Looking back a few years later upon my visit to the Spiral Jetty, I realize now that in photographing the legendary earthwork "flying past," my own expectations had very much shaped the veiled site that I finally found. For in thinking further about what was experienced that day, it's clear that I was carrying with me at the time a remarkably fixed image of what the Spiral Jetty was supposed to look like, or had 
looked like in 1970, the year of its completion and just prior to its inundation and disappearance. And the picture that I expected to see once arriving was of course largely derived from the many photographs already encountered in the growing archive surrounding Smithson's earthwork, images always present in any discussion of the Spiral Jetty. Over the years, like everyone else, I'd seen the various photographs again and again in books, magazines and journals, and with time I'd come to virtually believe in them, to take them for the remote earthwork that they so vividly depicted. For the photographs of the Spiral Jetty had in a manner of speaking, as Roland Barthes described the "violence" of such pictures, "fill[ed] the sight by force" (91), effectively covering the earthwork, filling the site with its images, like water rising over stones. No doubt, it was therefore a kind of composite photograph of Smithson's earthwork-taken from various angles and elevations, from up close and from afar-that accompanied me as I arrived at the location of the Spiral Jetty in 1998.

In traveling so far to find the Spiral Jetty, however, it now appears that I had in a very real sense gone to Utah in order to see and photograph what had always already been a photograph for me. It seems indeed that I made the long journey in order to visit the familiar picture projected onto the scene, to confirm the flat image laid out upon the lake, corroborating my transported, textual perceptions of the earthwork as applied to the empty landscape. Strangely, it appears that I was somehow seeing the photograph, seeing photographically (and then photographing it), not the object itself, but the now iconic image of the object, the aura-filled snapshots as they had become indelibly imprinted upon a kind of collective (unconscious) imagination, the familiar pictures that had in large part come to constitute Barthes' "shared hallucination," the craved place of the Spiral Jetty's believed, beloved appearance. The images of the earthwork, as Rosalind Krauss and so many others had described and used them, could now be virtually entered and walked within, seen before the eyes.

But, as already described, confirmation and corroboration of the Jetty's well-known photographs was not at all what I found once I arrived at the actual location. What I'd always pictured the earthwork to look like was not the picture that I finally encountered at the site. For the photographs accompanying me that day were nowhere to be seen, with barely a trace of the photographed object left behind-the broken asphalt on the shore, the scattered stones in the water. Yet in thinking through the unsettling discrepancies of image and expectation, memory and matter, appearance and disappearance, what $\operatorname{did}$ I find and feel on that strange and wonderful day in Utah and what, in the aftermath of my quite literal disillusionment, remains to be seen of such a perplexing site? As Eduardo Cadava has asked in his own study of Smithson, "What happens 
when our eyes meet what they cannot see? What happens when they encounter what cannot be encountered? In what way is sight essentially linked to an experience of ruin that ruins not only experience but sight itself? Why is it that . . Robert Smithson suggests that it is the task of the artist to reconstruct our 'inability to see'?" (5).

Returned to that time in 1998, remembering my own experience of ruin-a ruined experience-and reconstructing perhaps my own "inability to see" the Spiral Jetty, I remember looking out over the vast expanse of the lake, knowing where the earthwork once was, seeing it, notseeing it, the imagined form projecting invisibly out over the waters, "veiled in its very swiftness." With my camera carefully aimed, I photographed the disappeared photograph, the object vanished and vanishing, the flash of a memory "produc[ing] ... " as Bergson described it, "the effect of a ghost whose mysterious apparitions must be explained by special causes" (145). The archived picture before mein the blink of an eye, the click of a camera-seeing before the eyes see, the memory and the matter coupling into consciousness, a kind of ghosting from off the lake's surface. A shimmering reflection, an image of the earthwork seemed about to shape and congeal into its remembered substance- to appear or not to appear (that is the question) - the picture performing before me in what Bergson spoke of as a "work of adjustment, something like the focusing of a camera" (134).

And then, abruptly, as though in looking too hard and for too long-expecting to see too much-the chemical emulsions that had once fixed the familiar image of the photographed landscape (as a landscaped photograph) would seem to have somehow become reactivated, the picture returned to particles of light and fluid, the expansive site absorbing the memoried object. I wondered if I was seeing something of what Smithson had described elsewhere as the "... little oceans with right angles (called photographs)" (366). From the adjacent hill, I looked out at a picture now vanished-as though witnessing the ruined reversal of a photograph's development into a kind of de-composition of itself, the image of the earthwork fading back into blank, dissolving into water. Perhaps my eyes had finally reached their own threshold of sustainable perception, exhausting the sight and finally blinding the vision, ruining the scene, through their own strained exertions. "The ruin does not supervene," Derrida writes in Memoirs of the Blind, "like an accident upon a monument that was intact yesterday. In the beginning there is ruin. Ruin is that which happens to the image from the moment of the first gaze .... The ruin is not in front of us; it is neither a spectacle nor a love object. It is experience itself .... Ruin is, rather, this memory open like an eye ... that lets you see without showing you anything at all ..." (68-69).

Appearance and disappearance, my memory was "open like an eye" onto this ruined site, photographing the photographs of it. 
"Concentrate your mind on that sensation," Henri Bergson wrote, "and you will feel that the complete image is there, but evanescent, a phantasm that disappears just at the moment when motor activity tries to fix its outline" (86-87). The dialectical play of my own perceptions was arising from neither the earthwork (which had vanished), nor the photographs (which were not present), but somewhere indeterminately in between, bouncing off one another and in the process creating an affective awareness of the Spiral Jetty's immediate absence. The earthwork's very vacancy presented itself, performed itself, as vacancy, as I looked (through the viewfinder) literally onto nothing, and saw it, however fleetingly, as the tension between presence and absence, image and expectation. The Spiral Jetty was there, not there, seen, not seen, but something of the earthwork's absence was finally felt, the dimensions of its disappearance momentarily determined. The passing vision before me, the picture before my eyes, reminds me now of Gloucester in King Lear, seeing how "this world goes"- "O ruined piece of nature, this great world / Shall so wear out to naught" (337) — "seeing feelingly" the presence/absence before his blinded eyes, seeing indeed more than was there to be seen-something more than the sight itself.

\section{Notes}

${ }^{1}$ The Spiral Jetty's brief reemergence was documented and discussed in an article by Jean-Pierre Criqui, Artforum, summer 1994: 80-81.

2 The Spiral Jetty, during its construction and immediately following its completion, was photographed most thoroughly by Gianfranco Gorgoni.

${ }^{3}$ Smithson attributed his own initiatives toward land art as in part emerging from his experience working as an "artist-consultant" for an architectural firm and his finally unfulfilled "aerial art" projects intended for the Dallas-Fort Worth airport that were to be seen from planes in the air. Smithson writes: "I invented this job for myself as artistconsultant [for an architectural firm], and for about a year and a half, from 1965 through 1966, I went there and talked with the architects. And that's where the mapping and the intuitions in terms of the crystal structures really took hold in terms of areas of land-I was dealing with grids superimposed on large land masses, so that the inklings of the earthworks were there" (Smithson, Writings 290-291).

${ }^{4}$ Gary Shapiro writes, "As a voracious and eclectic reader, [Smithson] absorbed writers like Roland Barthes, Claude Levi Strauss, and Michel Foucault, years before they began to have a noticeable impact on the American intellectual and artistic scene, and he developed his own critique of structuralism, which he called 'destructuration', that both parallels and gives a distinctively American accent to what has come to be known as deconstruction" (3).

5 "Once, when asked what he would do if the lake covered the Jetty, Smithson responded that he would build the piece fifteen feet higher-thus indicating his intention to keep weathering and change within strictly defined limits. After 1972, when the Jetty was underwater, he in fact planned to build it higher if the water level 
of the lake did not recede" (Hobbs 197).

${ }^{6}$ As Cézanne wrote in a letter to Emile Zola in 1866, "But you know all pictures painted inside, in the studio, will never be as good as the things done outside. When out-of-door scenes are represented, the contrasts between the figures and the ground are astounding and the landscape is magnificent. I see some superb things and I shall have to make up my mind only to do things out-of-doors" (Chipp 16).

${ }^{7}$ Indeed, this seems a hypothetical, theoretical voyage that Utah's geographic remoteness has conveniently precluded from very often happening. In fact, many observers over the years have described the Spiral Jetty, not as invisible, but instead as "inaccessible," as if-above or below water-the earthwork was literally located beyond its own visitation.

${ }^{8}$ For instance, Gary Shapiro in his recent book on Smithson (the cover of which features a particularly striking, solarized photograph of the Jetty) placed the issue of the Jetty's disappearance in the Heidegerrian terms of "earth" and "world," writing: "A simple observation of the jetty's condition of being under water since 1972 might lead to the conclusion that earth has won its battle with world here. But the work, we should remember, is not identical with the fifteen hundred-foot coil that is now under the surface of the Great Salt Lake ..." (Shapiro 135).

${ }^{9}$ The term "theatricality" entered such art world discussions in the now famous debates (of which Smithson actively participated) emerging from Michael Fried's essay "Art and Objecthood." Artforum, June 1967.

${ }^{10}$ Both of the photographs used by Krauss were taken by Gianfranco Gorgoni.

${ }^{11}$ And Krauss must certainly have known about the Jetty's disappearance by the time her book was reprinted in 1983.

${ }^{12}$ Smithson frequently stressed the important aspect of travel in his work. For instance: "The site [in dialectical relation to his non-site] is a place you can visit and it involves travel as an aspect too" (Smithson, Writings 181); "It is a piece [Smithson's Yucatan 'mirror-displacements'] that involves travel. A lot of my pieces come out of the idea of covering distances .... I first got interested in places by taking trips and just confronting the raw materials of the particular sectors before they were refined into steel or paint or anything else" (192); and then there's the travel away from the city: "When the artist goes to the desert he enriches his absence and burns off the water (paint) from his brain. The slush of the city evaporates from the artist's mind as he installs his art" (109).

${ }^{13}$ In his 1967 essay, "A Tour of the Monuments of Passaic, New Jersey," Smithson describes—as he walked about Passaic, New Jersey—something quite similar to this uncanny, photographic phenomenon: "Noon-day sunshine Cinema-ized the site, turning the bridge and the river into an over-exposed picture. Photographing it with my Instamatic 400 was like photographing a photograph that was made of wood and steel..." (Smithson, Writings 70).

${ }^{14}$ From Shakespeare's Sonnet 77: “. . . Look what thy memory cannot contain, / Commit to these waste blanks, and thou shalt find / Those children nursed, delivered from they brain, / To take a new acquaintance of thy mind ...." (265).

\section{Works Cited}

Barthes, Roland. Camera Lucida: Reflections on Photography. Trans. Richard Howard. New York: Hill and Wang, 1981. 
Baudelaire, Charles. Baudelaire: Selected Writings on Art and Artists. Trans. P.E. Charvet Cambridge: Cambridge UP, 1972.

Benjamin, Walter. Illuminations. Ed. Hannah Arendt. Trans. Harry Zohn. New York: Schocken Books, 1969.

Bergson, Henri. Matter and Memory. Trans. N.M. Paul and W.S. Palmer. New York: Zone Books, 1991.

Cadava, Eduardo. "Irreversible Ruins." Ruins in Reverse: Time and Progress in Contemporary Art. Ed. Grant Kester (Cepa Gallery: Buffalo, Sep. 1998Mar. 1999). 5-8.

Chipp, Herschel B. Theories of Modern Art: A Source Book by Artists and Critics. Berkeley: U of California P, 1968

Derrida, Jacques. Memoirs of the Blind: The Self-Portrait and Other Ruins. Trans. Pascale-Anne Brault and Michael Naas. Chicago: U of Chicago P, 1993.

Hobbs, Robert. Robert Smithson: Sculpture. Ithaca: Cornell UP, 1981.

Kant, Immanuel. Critique of Judgment. Trans. Werner S. Pluhar. Indianapolis: Hackett Publishing Co., 1987.

Krauss, Rosalind E.. Passages in Modern Sculpture. Cambridge: MIT P, 1977.

Owens, Craig. “The Allegorical Impulse: Toward a Theory of Postmodernism." Art After Modernism: Rethinking Representation. Ed. Brian Wallis. New York: The New Museum of Contemporary Art, 1984. 202-235.

Proust, Marcel. Time Regained in Remembrance of Things Past, Volume III. Trans. C. K. Scott Moncrieff and Terence Kilmartin. New York: Random House, 1981.

Santayana, George. "Scepticism and Animal Faith." The Philosophy of Santayana. New York: Charles Scribner’s Sons, 1953. 375-402.

Shakespeare, William. King Lear. Ed. R. A. Foakes. London: Arden, 1997.

— Shakespeare's Sonnets. Ed. Katherine Duncan-Jones. London: Arden, 1998.

Shapiro, Gary. Earthwords: Robert Smithson and Art after Babel. Berkeley: U of California P, 1995.

Smithson, Robert. Robert Smithson: The Collected Writings. Ed. Jack Flam. Berkeley: U of California P, 1996.

—. Interview with Willoughby Sharp, 1968, transcribed in Suzaan Boettger, ed, "Degrees of Disorder," Art in America (Dec. 1998). 75-81. 